\title{
Construction Productivity Analysis for Asphalt Concrete Pavement Rehabilitation in Urban Corridors
}

\author{
Submitted to A2F05 - CONSTRUCTION MANAGEMENT
}

\section{Paper No.: 02-2876}

\begin{tabular}{|c|c|}
\hline & \\
\hline Eul-Bum Lee* & C. William Ibbs \\
\hline $\begin{array}{l}\text { Assistant Research Engineer } \\
\text { University of California, Berkeley } \\
\text { Institute of Transportation Studies } \\
\text { Pavement Research Center }\end{array}$ & $\begin{array}{c}\text { Professor } \\
\text { University of California, Berkeley } \\
\text { Department of Civil and Environmental Engineering } \\
\text { Construction Engineering and Management }\end{array}$ \\
\hline $\begin{array}{l}1353 \text { S. } 46^{\text {th }} \text { Street, Bldg. } 480 \\
\text { Richmond, CA } 94804 \\
\text { v: } 510-231-5694 \\
\text { f: } 510-231-9589 \\
\text { eblee@ uclink4.berkeley.edu }\end{array}$ & $\begin{array}{l}215 \text { McLaughlin Hall } \\
\text { University of California } \\
\text { Berkeley, CA } 94720 \\
\text { v: } 510-558-3475 \\
\text { f: } 510-643-8919 \\
\text { ibbs@ce.berkeley.edu }\end{array}$ \\
\hline John T. Harvey & Jim St. Martin \\
\hline $\begin{array}{l}\text { Associate Research Engineer \& } \\
\text { Associate Adjunct Professor }\end{array}$ & $\begin{array}{c}\text { Executive Director } \\
\text { Southern California Asphalt Pavement Association }\end{array}$ \\
\hline $\begin{array}{l}\text { University of California at Berkeley } \\
\text { Pavement Research Center }\end{array}$ & $\begin{array}{l}13697 \text { Hwy 94, \#2000 } \\
\text { Jamul, CA } 91935\end{array}$ \\
\hline $\begin{array}{l}1353 \text { S. } 46^{\text {th }} \text { Street, Bldg. } 480 \\
\text { Richmond, CA } 94804 \\
\text { v: } 510-231-9513 \\
\text { f: } 510-231-9589 \\
\text { jharvey@ euler.berkeley.edu }\end{array}$ & $\begin{array}{c}\text { v: (800) 734-9996 } \\
\text { f: (800) 734-9181 } \\
\text { jstmartin@ apaca.org }\end{array}$ \\
\hline
\end{tabular}

November 5, 2001

Word Count $=$ Total 7,432 $(5,432+6$ Figures and 2 Tables $)$

* Corresponding Author 


\begin{abstract}
This paper presents the results of a constructability and productivity analysis for the Caltrans Long Life Asphalt Concrete Pavement Rehabilitation Strategies (LLACPRS). With the assistance of California asphalt concrete paving contractors, the analysis explored the effects on construction productivity of rehabilitation materials, design strategy (crack seat and overlay, full-depth replacement), layer profiles, AC cooling time, resource constraints, and alternative lane closure tactics. Deterministic and stochastic analysis programs were developed. A sensitivity study was performed that examined construction production within a 55-hour weekend closure. Weekend closures were also compared to continuous closures.

Demolition and AC delivery truck flows were the major constraints limiting the AC rehabilitation production capability. This study concludes that efficient lane closure tactics designed to work with the pavement profile can minimize non-working time to increase the construction production efficiency. The results of this study will help road agencies evaluate rehabilitation strategies and tactics with the goal of balancing the maximization of production capability and minimization of traffic delay during urban rehabilitation.
\end{abstract}




\section{INTRODUCTION}

\section{Caltrans Long-Life Pavement Rehabilitation Overview}

The California highway system has over 78,000 lane-kilometers (24,000 centerline- kilometers). A large portion of this highway system has been exposed to heavier traffic volumes and loads than those for which it was originally designed. Consequently, the transportation network has deteriorated significantly. The deterioration of the highway pavements has started to adversely affect road user safety, ride quality, vehicle operating costs, and the cost of highway maintenance (1). "1999 State of the Pavement" by the California Department of Transportation (Caltrans) indicated that 25,000 lane-km required corrective maintenance or rehabilitation with 11,260 lane-km needing immediate rehabilitation (2).

In 1998, Caltrans launched the long-life pavement rehabilitation strategies (LLPRS) program to rebuild approximately 2,800 lane-km of the state highway network over 10 years. The criteria for urban freeway candidates for long-life pavement rehabilitation were poor structural condition and ride quality and minimum 150,000 Average Daily Traffic or 15,000 Average Daily Truck Traffic. Most of the rehabilitation candidate projects are in urban corridors of Southern California and the San Francisco Bay Area. The original goals of LLPRS are: (a) 30 years of service life, (b) minimal maintenance, and (c) sufficient production capability to rehabilitate 6 lane-km within a construction window of 55 hours: 10 p.m. Friday to 5 a.m. Monday (3). Caltrans proposed the short weekend construction window to minimize traffic disruptions. In order to complete the desired 2,800 lane-km of long-life pavement in ten years, Caltrans needs to rehabilitate approximately 6 lane-km of pavement per weekend closure.

Caltrans LLPRS consists of two sub-categories: LLACPRS for Asphalt Concrete Rehabilitation and LLCPRS for Concrete Rehabilitation. In this paper, PCC (Portland Cement Concrete) pavement rehabilitation with Asphalt Concrete (LLACPRS) is referred to as AC Rehabilitation; PCC pavement rehabilitation with Concrete (LLCPRS) is called Concrete Rehabilitation. For both strategies, the assumed existing PCC pavement to be rehabilitated is the same, 200 to $225 \mathrm{~mm}$ of plain, jointed PCC; 100 to $150 \mathrm{~mm}$ of cement treated base (CTB); some type and thickness of aggregate subbase; and the compacted natural subgrade.

\section{Previous and Ongoing Research Works for LLPRS}

The research described in this paper for AC Rehabilitation is a part of the five-stage study of construction productivity analysis for LLPRS conducted by the research team at the University of California, Berkeley (UCB) since 1998 (4). The five stages are:

- Concrete Constructability Analysis: Caltrans sponsored constructability analysis for Concrete Rehabilitation (LLCPRS), already completed $(5,6)$.

- Case Study for the Concrete Analysis: The concrete constructability analysis was validated and calibrated with a case study of the Caltrans demonstration project on I-10 in Pomona in 1999, sponsored by the Innovative Pavement Research Foundation (IPRF) and the Federal Highway Administration (FHWA) (7, 8).

- Asphalt Concrete Construction Productivity Analysis: Caltrans sponsored constructability analysis for AC Rehabilitation (LLACPRS), completed (9) and presented in this paper.

- Case Study for Asphalt Concrete Analysis: A Caltrans sponsored case study for AC Rehabilitation is underway on the Caltrans demonstration project on I-710 (Long Beach Freeway) with scheduled completion in 2002 for the validation and calibration of the AC construction productivity analysis model (4).

- Knowledge-based Simulation Software for Constructability Analysis: "Knowledge-based simulation" software is being developed (with scheduled completion in 2002), sponsored by four state departments of transportation (California, Minnesota, Texas, and Washington state). This software, with deterministic and stochastic analysis modules like those used in this paper and previous studies, is intended for use by the road agencies as a construction planning tool.

\section{Research Approach}

The basic elements of the construction productivity analysis, such as construction windows, paving materials, and design profiles were identified by experienced staff at Caltrans and UCB. These elements were checked and adjusted through a series of technical meetings with the Southern California Asphalt Pavement Association (SCAPA) and Caltrans pavement and material engineers. Field trips were made to pavement construction sites in 
Southern California to gather field data, especially regarding resource constraints, scheduling aspects, and cooling time information.

As an analysis tool, a prototype simulation program was developed linking all parameters interactively in the hierarchical structure of the analysis options. This runs on commercially available spreadsheet software (Microsoft ${ }^{\circledR}$ Excel). The program was designed to determine the maximum production capability of the rehabilitation and communicate the results in tables and graphs (4). Because of the space limit, the details of the analysis program are not included in this paper. A journal paper is being written by the authors separately that will include more details about the simulation program.

\section{Research Objectives and Scope}

As the initial objective of the AC construction productivity analysis, the desired output was the maximum production capability in terms of lane-km within the 55-hour weekend closure window. This output was used for production comparison of different rehabilitation strategies, resource constraints, design profiles, and lane closure tactics. In addition, the 55-hour weekend closure was compared with continuous construction and with daytime construction.

Two different AC Rehabilitation strategies were analyzed: CSOL (Crack Seat and Overlay) and Full-Depth Replacement. The AC construction productivity analysis procedure has been implemented for both deterministic analysis, where input parameters involved in the rehabilitation processes are fixed with representative values, and stochastic analysis, where the input parameters are treated as random variables.

The AC construction productivity analysis developed in this study will aid transportation agencies in their decision-making processes for scheduling rehabilitation projects based on their estimated construction duration, preliminary selection of optimal design and construction strategies and tactics, evaluation of the impact of lane closure on productivity, and effective communication of project duration with the public and other project stakeholders such as local governments and businesses.

\section{EXPERIMENT DESIGN FOR THE ANALYSIS}

\section{Analysis Assumptions}

To decrease the number of independent variables in construction productivity analyses, the following assumptions were made:

- Construction window: 55-hour weekend or continuous closure.

- Traffic barriers were installed prior to the weekend construction window.

- For Full-Depth AC Replacement, only the truck lanes (in most cases two lanes) were replaced.

- For CSOL the whole freeway including shoulders on both sides was subjected to the rehabilitation.

- Before a subsequent lift of asphalt concrete is placed, the current lift must cool to a maximum temperature of $74^{\circ} \mathrm{C}\left(165^{\circ} \mathrm{F}\right)$.

- Prior to the weekend closure, the existing PCC pavement was pre-cut and ready for removal for Full-Depth AC Replacement, and the PCC slab was cracked and seated for CSOL.

\section{Hierarchical Structure of the Analysis Options}

Based on the information gathered from the industry (SCAPA and Caltrans), previous concrete constructability analysis, and a comprehensive literature review, the potential elements most likely to govern the production capability of AC Rehabilitation projects were identified and summarized (4). An experimental design was developed based on the hierarchical structure of these AC construction productivity variables (Figure 1). Because the choice of the pavement design profile determines the main components of AC Rehabilitation, the detailed layer profiles and work plans for each option of Crack Seat and Overlay (CSOL) and for Full-Depth AC Replacement are fully described separately as following.

\section{Crack Seat and Overlay (CSOL) Option}

Two pavement layer profiles for CSOL were compared with respect to production capability (Figure 2):

- CSOL Layer Profile "A": $230 \mathrm{~mm}$ overlay

- CSOL Layer Profile "B": 200 mm overlay 
These layer profiles were selected from preliminary design evaluations for a California freeway with heavy truck traffic by the UCB Pavement Research Center (PRC), and provide an indication of the impact of different layer profiles on rehabilitation production capability. Actual structural sections must be designed for each project location. The cooling hours in the right hand column of each layer profile option in Figure 2 were calculated from a numerical cooling simulation program, MultiCool (10). After cleaning, sweeping, and tacking the concrete pavement, four lifts of hot mix asphalt will be placed on a cracked and seated existing PCC pavement surface. The interface between the first and second AC lift is a fabric helping postpone reflective cracking in the AC overlay. In typical California practice the fabric is placed on a tack coat while the first AC lift is still hot.

The major advantage of the CSOL option is that it does not require removal of the existing PCC slab, unlike PCC pavement reconstruction or Full-Depth AC Replacement. But the disadvantages of CSOL are that all lanes and shoulders must be paved to maintain uniform elevation, and the overlay cannot be placed underneath bridge overpasses unless there is adequate clearance between the freeway and the bridge.

\section{Lane Closure Tactics for CSOL}

Efficient lane closure tactics are the biggest concern for any state department of transportation (DOT) to balance inconvenience to road users and the production capability of the rehabilitation. Based on consultation with SCAPA and Caltrans engineers, two alternative lane closure tactics for the CSOL option were defined and compared in the analysis:

- CSOL Full Closure

- CSOL Half Closure

\section{CSOL Full Closure}

In the case of CSOL Full Closure, one direction of the freeway is completely closed for rehabilitation by switching the traffic to the other side, utilizing counter-flow traffic. All four lanes plus shoulders on both sides will be overlaid completely within the 55-hour weekend closure, lane-by-lane and layer-by-layer, sequentially (see Figure $3 \mathrm{a}$ for the freeway lane numbering convention used in this paper). The detailed sequence of the CSOL Full Closure rehabilitation starts with one paving machine beginning to place the first lift of hot mix asphalt from Truck Lane 2 (T2). Then, the paving team travels back to the starting point to place the first lift of the next lane (T1). This process continues until all lanes have been paved with the first lift of AC. With the same process this paving process is repeated until all four AC lifts have been paved on all four traffic lanes. The shoulders on both sides are assumed to receive the overlay simultaneously with the main traffic lane overlays.

\section{CSOL Half Closure}

Alternatively, CSOL Half Closure will close only two out of four lanes in one direction during the weekend closure. This allows two lanes to be open to traffic in the direction of the rehabilitation and four lanes of traffic to be open in the opposite direction. The traffic would be separated from the construction zone by a mobile concrete barrier (MCB) between Passenger Lane 2 (P2) and Truck Lane 1 (T1), as shown in Figure 3a. The CSOL Half closure option has the following two sub-options, depending on the completion of overlay paving within a single weekend closure:

- $\quad$ CSOL Half Closure Full Completion

- CSOL Half Closure Partial Completion

- CSOL Half Closure Full Completion: The detailed sequence of the CSOL Half Closure Full Completion option (Figure 3) is to place the first two lifts in lanes T1 and T2 at first. In the second stage, traffic would then be switched to the newly paved lanes (T1 and T2), and the rehabilitation work would move to the remaining two lanes (P1 and P2). In the third stage, the third and fourth lift on the two inner lanes (P1 and P2) will be placed immediately after the second stage is done. Traffic must then be switched again to move the traffic back to lanes P1 and P2. Finally, the fourth stage of construction completes lifts three and four on lanes T1 and T2. This option introduces the possibility of wasting time waiting for AC cooling, and the time inefficiency of switching the traffic flows twice. One alternative solution to overcome this potential problem with the CSOL Half Closure Full Completion option is the CSOL Half Closure Partial Completion option, as described below. 
- CSOL Half Closure Partial Completion: The only difference between CSOL Half Closure Partial Completion and CSOL Half Closure Full Completion is that in the first weekend closure, the first two AC lifts are placed on all four lanes with a similar sequence used for the CSOL Half Closure Full Completion option. This requires only one traffic switch from lanes $\mathrm{T} 1$ and $\mathrm{T} 2$ to $\mathrm{P} 1$ and $\mathrm{P} 2$ during the weekend closure. The remaining two lifts of AC are completed during the second weekend closure with a similar single traffic switch. The concern with this method is the structural performance of the first two AC lifts under traffic loading for one week.

\section{Full-Depth AC Replacement Option}

In the Full-Depth AC Replacement option, the existing PCC truck lanes (T1 and T2) are replaced with new asphalt concrete. The old PCC slab and CTB will be demolished and hauled away, and part of the aggregate base (AB) will be trimmed and re-compacted to accommodate the required depth of the new asphalt concrete pavement. The first lift of asphalt concrete will be a 76-mm rich bottom AC layer placed on top of the re-compacted AB. The profile of the existing PCC and new asphalt pavement (Full-Depth AC Replacement) with typical AC cooling times during summer weather in the Los Angeles basin are shown in Figure 4. The following two layer profiles (Figure 4) were selected by the UCB PRC based on preliminary design evaluations for a California freeway with heavy truck traffic:

- $\quad$ Full-Depth Layer Profile "A": $330 \mathrm{~mm}$ of AC

- Full-Depth Layer Profile "B": 406 mm of AC

In the case of the Full-Depth Layer Profile "A" option, the profile replacing the existing PCC slab, CTB, and $25 \mathrm{~mm}$ of $\mathrm{AB}$ has five lifts: a 76-mm (3-in.) rich bottom $\mathrm{AC}$ lift, three 76-mm lifts, and a 25-mm AC surface course (potentially open graded asphalt rubber). The Full-Depth Layer Profile "B" option has six lifts: a 76-mm (3in.) rich bottom AC lift, three 76-mm AC lifts, a 51-mm AC lift, and a 51-mm top lift. The existing PCC and CTB will be removed along with the top third $(102 \mathrm{~mm})$ of the aggregate base.

\section{Lane Closure Tactics for Full-Depth AC Replacement}

Two alternative lane closure tactics for the Full-Depth AC Replacement option were defined and compared in the analysis:

- $\quad$ Full-Depth AC Single-Lane Rehabilitation

- Full-Depth AC Double-Lane Rehabilitation

In the Full-Depth Double-Lane Rehabilitation scheme, the two truck lanes (T1 and T2) are demolished and rebuilt completely during one weekend closure, while in the Full-Depth Single-Lane Rehabilitation, only one truck lane is rehabilitated during the first weekend closure and the other truck lane is completed during the second weekend closure. The single- and double-lane rehabilitation concept for AC Rehabilitation is similar to the lane closure tactics for Concrete Rehabilitation described in Reference $(5,6)$. Note that the double-lane rehabilitation option for Full-Depth AC Replacement does not specify paving both lanes simultaneously, which is the case for Concrete Rehabilitation.

\section{Full-Depth AC Single-Lane Rehabilitation}

During the first weekend closure, two truck lanes (T1 and T2) will be closed to rebuild Truck Lane 2 (T2). As soon as the PCC slab and CTB are removed and the AB is trimmed, five or six lifts of asphalt concrete are placed sequentially lift-by-lift with a single paving team. Truck Lane 1 (T1) is used as the construction access for demolition and paving activities. During the following weekend closure, Truck Lane 1 (T1) will be rebuilt using the same procedure, i.e., two truck lanes (T1 and T2) will be closed and Truck Lane 2 (T2) will be used as the construction access.

A negative structural aspect of Full-Depth Single-Lane Rehabilitation is that the interlocking of AC lifts by overlapping of longitudinal joints between adjacent rehabilitated lanes (T1 and T2) is not possible. In addition, safe movement of the asphalt delivery trucks from the delivery lane to the paving lane has to be resolved because the initial elevation difference between the demolished lane and the access lane is between 330 and $406 \mathrm{~mm}$. This discharging constraint is more serious with the semi bottom dump truck, which has no side-dumping feature. 


\section{Full-Depth AC Double-Lane Rehabilitation}

For the Double-Lane Rehabilitation option, both truck lanes (T1 and T2) will be rebuilt during one weekend closure, which requires closing three lanes (P2, T1, and T2). Passenger Lane 2 (P2) is assigned as the construction access for demolition and paving. Truck Lane 2 (T2) will be used as access for paving Truck Lane1 (T1), and Passenger Lane 2 (P2) will be used as access for paving Truck Lane 1 because Truck Lane 2 will not be cool enough for delivery trucks.

\section{Construction Resource Constraints}

The major resource constraints limiting the production capability of the urban pavement rehabilitation, along with the number and capacity of each resource used in the deterministic analysis are listed below:

- $\quad$ One AC mixing plant for $200 \mathrm{~m}^{3} / \mathrm{hr}$

- $\quad 12$ demolition trucks per hour (25 ton capacity carrying $7 \mathrm{~m}^{3}$ of old concrete)

- $\quad 12 \mathrm{AC}$ delivery trucks per hour (25 ton capacity carrying $10 \mathrm{~m}^{3}$ of new asphalt concrete)

- $\quad$ One asphalt concrete paver $(4.5 \sim 7.5 \mathrm{~km}$ per hour speed, depends on the thickness of the paving lift)

Based on the experience of several AC contractors, the asphalt delivery trucks (SBT: Semi-Bottom Truck) and demolition hauling trucks (DT: Dump Truck) were found to be the primary constraints while the mixing plant and paver were the secondary constraints. The AC compaction rollers were not a major constraint for $\mathrm{AC}$ Rehabilitation. Although the mixing plant and paver are not the critical resource constraints governing production capability, contractors typically believe these two resources are the most crucial pieces of equipment for the success of the project. The locations of the plant and the demolition dumping area with respect to the construction site are parameters that strongly influence productivity because they directly affect the turnaround time of the demolition and delivery trucks. Sufficient space is also needed at the asphalt concrete plant for the aggregate stockpiles.

\section{Detailed Process of the Productivity Analysis for AC Rehabilitation}

The process of the simulation software developed for the construction productivity analysis of AC Rehabilitation and the values evaluated in this study are summarized as follows:

1. Set the rehabilitation project length as an objective: 6 lane-km.

2. Set up a construction window: 55 hours.

3. Choose design profile: CSOL or Full-Depth AC Replacement.

4. Decide layer profile: Layer Profile "A" or "B".

5. Consider lane closure tactics: Full- or Half-Closure (CSOL), or Single- or Double-Lane (Full-Depth AC).

6. Calculate quantity of materials. Quantify the volume of demolition (Full-Depth AC) and asphalt concrete to produce and deliver.

7. Carry out a simple CPM (Critical Path Method) scheduling. The net working hours for demolition (Full-Depth AC case only) and AC paving are calculated.

8. Determine the required number of resources and capacity to handle the volume of the materials.

9. Apply resource constraints. The number of hauling and delivery trucks per hour is limited by the minimum cycle time for loading or unloading and the turn-around time.

10. Introduce linear scheduling technique. Linear scheduling methods are applied to identify the maximum production capability given the resource constraints and progress of the resources involved $(4,11)$. Linear scheduling is especially helpful in balancing allocation of time between the paving and demolition (Full-Depth AC Replacement case only) activities.

11. Check cooling time. If the AC lift has not cooled to the specified stop temperature from the cooling time analysis, the total number of net working hours is decreased and the linear scheduling process is re-run (go to the step 7 above).

12. Finalize maximum production capability. The prototype simulation program picks out the most constraining resource at the calculated maximum production capability of the AC rehabilitation project. 
13. Implement a stochastic analysis. Based on the same process used for the deterministic productivity analysis, a stochastic productivity analysis can be run by varying the resources and scheduling parameters with defined Probability Distribution Function (PDF) (4).

\section{Cooling Time Simulation Software}

In multi-lift (4 to 6 lifts) construction for fast-track AC Rehabilitation, paving is scheduled for a number of lanes (typically 2 to 4 lanes) within the limited time of the weekend closure. To optimize paving time, the next lift is placed immediately after the compaction of the first lift and therefore the first lift must cool to the maximum allowable AC temperature before the next lift is placed. For the AC construction productivity analysis a computer simulation program (MultiCool) was used to predict the temperature profiles in multi-lift AC Rehabilitation (10). In 1999, a research team at the University of Minnesota was contracted by the UCB PRC to update a previously developed program (Pave Cool) to predict the cooling time of multi-lift asphalt concrete pavements. The software uses Fourier's Second Law to deal with heat transfer in a pavement structure and the finite difference method to solve a series of heat flux equations.

A validation study of MultiCool was performed using experimental and field data from several AC paving projects in California. The field data correlated adequately with software predictions for single and multi lift construction for use in construction productivity analysis (10).

\section{RESULTS OF THE AC ANALYSIS}

The production capability of AC rehabilitation can be measured in two different ways: centerline-meters and lanemeters. Lane-meters is the product of the number of rehabilitated lanes and centerline-meters. Two types of calculation were implemented in determining the maximum production capability of AC Rehabilitation as follows.

\section{Deterministic and Stochastic Analyses}

- Deterministic analysis: Major input parameters such as resource availability, scheduling factors, and delay for AC cooling time were treated as constants without variations. The purpose of the deterministic analysis was to measure the sensitivity of the production capability of AC Rehabilitation to all input parameters.

- Stochastic analysis: These input parameters were treated as random variables with defined probability distributions. For Monte Carlo simulations Crystal Ball@ (12) was used as the stochastic engine along with the UCB prototype analysis spreadsheet for deterministic analysis.

The distribution of the parameters as random variables for the stochastic analysis was defined as realistically as possible using resource reference information from AC field data and the I-10 project concrete case study (4). The mean of the distribution is the same as the typical value for the deterministic analysis. The parameters were randomly generated and combined to complete 1,000 Monte Carlo simulations in the analysis spreadsheets. As the sum of the independent input parameters of random variables, the production capability has an approximate normal distribution, based on the "Central Limit Theorem" (13).

\section{CSOL Production Capability}

\section{Result of Deterministic and Stochastic Analyses}

Figure 5 summarizes the results of the CSOL deterministic and stochastic analyses in terms of total lane-meters for four-lanes rehabilitation categorized into different intervals of likelihood, i.e., lower bound, mean, and upper bound, based on a "one-standard deviation" of confidence interval around the mean $(4,13)$. The mean production capability from the stochastic analysis is very close to the deterministic analysis when using an average of 12 asphalt delivery trucks. The deterministic analysis showed that the production capability increases for all options as the AC delivery trucks per hour increased until the next constraint (in this case the capability of the AC mixing plant) begins to control the production capability. The stochastic analysis sensitivity chart showed that the cycle time of the asphalt delivery trucks (SBT) is the most influential variable effecting the rehabilitation production capability. 


\section{Production Comparison for the CSOL Option}

Table 1 compares the relative average production capability predicted from the CSOL stochastic analysis between each rehabilitation option. Table 1 also includes the number of hours of delay due to waiting for hot AC to cool and switching of traffic between lanes. The results show that the amount of delay greatly affects the overall productivity of the rehabilitation.

Layer Profile "B" (200 mm overlay) has approximately 12 percent more production capability than Layer Profile "A" (230 mm overlay), which is almost the same as the ratio of the overlay thicknesses of the two pavement profiles. On average, the Half Closure Full Completion case is approximately 20 percent less productive than the Full Closure Full Completion option. But, in the Half Closure Partial Completion option, the delay caused by AC cooling is negligible and therefore the production capability was found to be almost the same as the Full Closure Full Completion case, i.e., with only a 3 percent loss in production capability although two out of four lanes are always open to traffic. The only issue to resolve in that case is the impact on pavement life of opening two out of the four lifts of $\mathrm{AC}$ for one week to normal urban freeway traffic.

\section{Full-Depth AC Replacement Production Capability}

\section{Results of Deterministic and Stochastic Analyses}

The results of the deterministic and stochastic analyses for Full-Depth AC Replacement (for the Single- and Double-Lane cases for each layer profile) are summarized in Figure 6. The graph shows the potential range of rehabilitation productivity, (i.e., lower and upper bounds with mean), compared with the results of the deterministic analysis. The stochastic analysis sensitivity chart showed that the overall production of the Full-Depth AC Rehabilitation was most sensitive to the number of demolition teams, the number of dump trucks per hour, the efficiency of the dump trucks, the number of asphalt delivery trucks per hour, and finally, the efficiency of the AC delivery trucks in that order.

\section{Productivity Comparison of Full-Depth AC Replacement}

Summarizing the stochastic analysis for Full-Depth AC Replacement, the production capability for Layer Profile "B" (406 mm AC) was about 80 percent that of Layer Profile "A" (330 mm AC). This reduction is proportioned to the extra amount of asphalt thickness that is required for Layer Profile "B". This suggests that the production difference was mainly the result of the depth of existing pavement to be removed and the depth of new asphalt concrete to be delivered.

The Single-Lane Rehabilitation strategy was about 10 percent more productive than the Double-Lane Rehabilitation strategy because fewer working hours were spent waiting for AC cooling compared with the doublelane option. In the concrete constructability analysis $(5,6)$, Double-Lane paving was more productive than SingleLane paving because both lanes were paved simultaneously and the constraints for Single- and Double-Lane paving were different.

\section{Effects of Changing Construction Window}

A 55-hour weekend closure, as the basic construction window, was compared with two additional construction windows: "continuous closure/continuous operation (three shifts, 24 hours per day)" and "continuous closure/daytime operation (two shifts, 16 hours per day)". For all three of these construction windows, the time required to rebuild a 5-km segment of the freeway with 4 lanes for one direction was analyzed, i.e., the rehabilitation scope would be 20 lane-km (4 traffic lanes) for the CSOL option (Full Closure Full Completion), or 10 lane-km (two truck lanes) for the Full-Depth AC Replacement option (Single-Lane Rehabilitation).

Table 2 shows the number of weeks or weekends needed to accomplish this 5-km hypothetical rehabilitation project for each proposed construction window. Table 2 also shows the effect of working 16 hours per day ( 2 shifts) or 24 hours per day ( 3 shifts). In the case of the CSOL option, using Profile "A" as an example, the continuous closure/continuous operation can finish the project within 1.2 weeks ( 8 days), while using only 55-hour weekend closures requires 4.2 weekends (9.6 days) to complete the same project, i.e., the continuous closure/continuous operation enables the CSOL project to be finished 15 percent faster compared to weekend-only closures. In the case of the Full-Depth AC Replacement option, using Profile "A" as an example, the continuous closure/continuous operation can finish the project within 1.4 weeks (10 days), while using only weekend closures 
requires 4.8 weekends (11 days) to complete the same project, i.e., the continuous closure/continuous operation enables the Full-Depth AC Replacement project to be finished 10 percent faster compared to weekend-only closures. However, continuous closure/continuous operation may not be realistic for many projects due to weekday traffic interruptions as well as additional costs, noise problems for nearby residents, and logistics.

\section{CONCLUSIONS}

This paper describes the processes and results of a constructability and productivity analysis performed to evaluate Caltrans Long Life Asphalt Concrete Pavement Rehabilitation Strategies (LLACPRS). The conclusions drawn from the analysis are:

1. The objective of the Caltrans LLACPRS to rehabilitate 6 lane-kilometers of truck lanes (3 centerlinekilometers) within a 55-hour weekend closure has a low probability of success, i.e., on average only 30 percent of this objective could be met with the Full-Depth AC Replacement option and 40 percent with the CSOL option.

2. Material delivery resources, especially dump trucks for demolition and delivery trucks for asphalt concrete supply, are the major constraints limiting the production. The total layer thickness for asphalt concrete proved to be a major determining element on the production capability. For example, on average the production capability of Full-Depth AC Replacement is about 60 percent of CSOL production within a weekend closure.

3. The most efficient lane closure tactic for CSOL is Half Closure Partial Completion, assuming that the impact on pavement performance of having two out of the four lifts of AC open to normal urban freeway traffic for one week is acceptable. For Full-Depth AC Replacement, Single-Lane Rehabilitation is much more efficient than Double-Lane Rehabilitation, although the negative aspect of the option is that good interlock of the longitudinal joint between the two lanes will be difficult to obtain.

4. The results of the asphalt concrete construction productivity analysis showed that the AC cooling time depended on the lane closure tactics and pavement profile. Efficient lane closure tactics along with adjustment of pavement profile will minimize non-working time and increase the production capability of the project. Flexibility in lift thicknesses within the limit of the total thickness permitted by the agency will aid in the development of efficient paving plans.

\section{ACKNOWLEDGEMENT}

This project was funded by the California Department of Transportation. The University of California, Berkeley research team would like to acknowledge the information and work contributed by Caltrans and the Southern California Asphalt Pavement Association, especially Mr. Jim St. Martin for his coordination work with industry representatives.

\section{APPENDIX: REFERENCES}

1. Pavement Consultancy Services, Guidelines and Methodologies for the Rehabilitation of Rigid Highway Pavements Using Asphalt Concrete Overlays, Beltsville, Maryland, 1991.

2. California Department of Transportation, 1999 State of the Pavement, Caltrans Maintenance Program, Pavement Management Information Branch, Sacramento, CA, 2000.

3. California Department of Transportation, Invitation to PCCP Lane Replacement Team Meeting, Sacramento, CA, 1997.

4. Lee, E.B., Constructability and Productivity Analysis for Long Life Pavement Rehabilitation Strategies (LLPRS), Ph.D. Dissertation, University of California, Berkeley, CA, 2000.

5. Lee, E.B., Ibbs, W., Harvey, J., and Roesler, J., Constructability and Productivity Analysis for Long Life Concrete Pavement Rehabilitation Strategies, University of California, Berkeley. Caltrans Report No. FHWA/CA/OR-2000/01. Sacramento, CA, 2000. 
6. Lee, E.B., Ibbs, W., Roesler, J., and Harvey, J., Construction Productivity and Constraints for Concrete Pavement Rehabilitation in Urban Corridors, In Transportation Research Record 1712, TRB, National Research Council, Washington, D.C., 2000, pp. 13-22.

7. Lee, E.B., Roesler, J., Harvey, J., and Ibbs, W., Case Study of Urban Concrete Pavement Reconstruction and Traffic Management for the I-10 (Pomona, CA) Project, Final Report, Contract No: DTFH61-99-X-00008, FHWA / IPRF (Innovative Pavement Research Foundation), Falls Church, VA, 2000.

8. Lee, E.B., Roesler, J., Harvey, J., and Ibbs, C., Case Study Of Urban Concrete Pavement Reconstruction On Interstate 10, Journal of Construction Engineering and Management, ASCE, Dec 2001 (scheduled to publish).

9. Lee, E.B., Ibbs, W., Harvey, J., and Roesler, J., Constructability and Productivity Analysis for Long Life Asphalt Concrete Pavement Rehabilitation Strategies, Draft Report, California Department of Transportation, Sacramento, CA, 2001.

10. Timm, D., Voller, V., Lee, E. B., Harvey, J., MultiCool: A Numerical Solution Program for Multi-Layer Cooling Time of Asphalt Concrete Pavement, The International Journal of Pavement Engineering, Accepted for publication, 2001.

11. Johnston, D., Linear Scheduling Method for Highway Construction, Journal of Construction Division, ASCE, Vol. 107, No. 2., 1981.

12. Crystal Ball 2000 User Manual, Decisioneering, Inc., Denver, Colorado, 2000.

13. Moder, J., Phillips, C., and Davis, E., Project Management with CPM, PERT, and Precedence Diagram ( $\left.3^{\text {rd }}\right)$. Van Nostrand Reinhold, New York, NY. 1983. 


\section{LIST OF TABLES}

Table 1 Production Comparison for CSOL Rehabilitation

Table 2 Comparison of the Effect of Different Construction Windows

\section{LIST OF FIGURES}

Figure 1. Hierarchical research structure for AC construction productivity analysis.

Figure 2. Two layer profiles for CSOL (Crack Seat and Overlay).

Figure 3. Detailed lane closure plan for CSOL Half Closure Full Completion.

Figure 4. Two layer profiles for Full-Depth AC Replacement.

Figure 5. Results of stochastic analysis for CSOL production.

Figure 6. Results of stochastic analysis for Full-Depth AC Replacement production. 
Table 1 Production Comparison for CSOL Rehabilitation

\begin{tabular}{|c|c|c|c|c|c|c|c|c|c|c|c|}
\hline & & & & & $\begin{array}{l}\text { of } \\
\text { Reh }\end{array}$ & & 1 & $\begin{array}{l}\mathrm{Cl} \\
\mathrm{met}\end{array}$ & for $C$ & & \\
\hline $\mathrm{Clo}$ & ure & & Ful & sur & & & & Hal & sure & & \\
\hline Complet & n Option & & & & & & & ion & & $\mathrm{Co}$ & $\begin{array}{l}\text { l } \\
\text { tion }\end{array}$ \\
\hline Layer & Profile & & & & & & & & & & \\
\hline Average & roduction ${ }^{1}$ & & & & & & & & & & \\
\hline Comp & rison $^{2}$ & & & & & & & & & & \\
\hline Delays & (hours) & & & & & & & & & & \\
\hline AC Cooling & $\begin{array}{c}\text { Traffic } \\
\text { Switching }\end{array}$ & 0 & 0 & 0 & 0 & 2 & 7 & 2 & 6.5 & 0 & 3 \\
\hline
\end{tabular}

${ }^{1}$ Stochastic analysis in terms of total lane-meters for four-lane rehabilitation

${ }^{2}$ Compared with CSOL Full Closure Full Completion Layer Profile "B" 
Table 2 Comparison of the Effect of Different Construction Windows

\begin{tabular}{|c|c|c|c|c|}
\cline { 2 - 5 } \multicolumn{1}{c|}{} & \multicolumn{3}{c|}{$\begin{array}{c}\text { Number of Weeks* or Weekends** Required to } \\
\text { Complete Rehabilitation }\end{array}$} \\
\hline Design Profile & \multicolumn{3}{c|}{ CSOL } & \multicolumn{2}{c|}{ Full-Depth AC } \\
\hline Layer Profile & Profile "A" & Profile "B" & Profile "A" & Profile "B" \\
\hline Thickness & $230 \mathrm{~mm}$ & $200 \mathrm{~mm}$ & $330 \mathrm{~mm}$ & $406 \mathrm{~mm}$ \\
\hline 55-hour Weekend Closure** & 4.2 & 3.7 & 4.8 & 5.9 \\
\hline $\begin{array}{c}\text { Continuous Closure } \\
\text { Daytime Operation (2 shifts)* }\end{array}$ & 1.8 & 1.6 & 2.1 & 2.6 \\
\hline $\begin{array}{c}\text { Continuous Closure } \\
\text { Continuous Operation (3 shifts)* }\end{array}$ & 1.2 & 1.1 & 1.4 & 1.8 \\
\hline
\end{tabular}



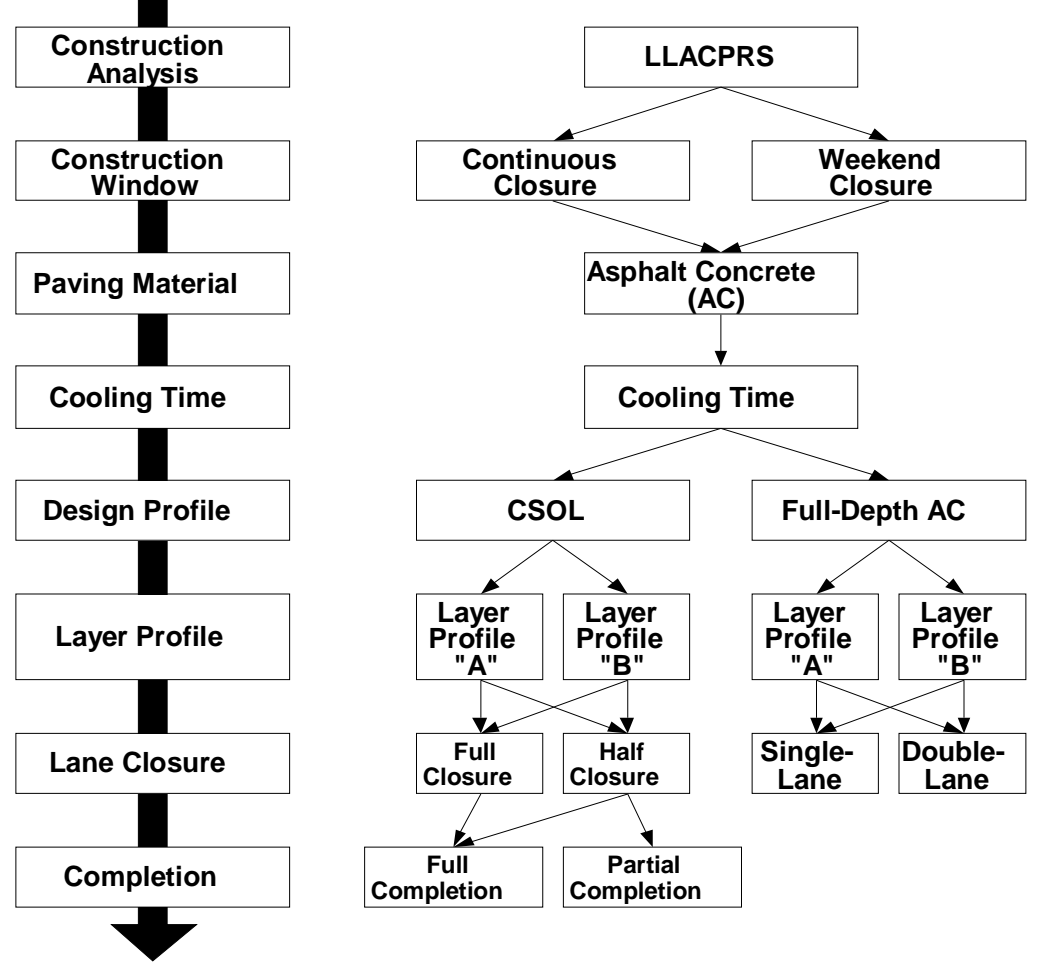

Figure 1. Hierarchical research structure for AC construction productivity analysis. 


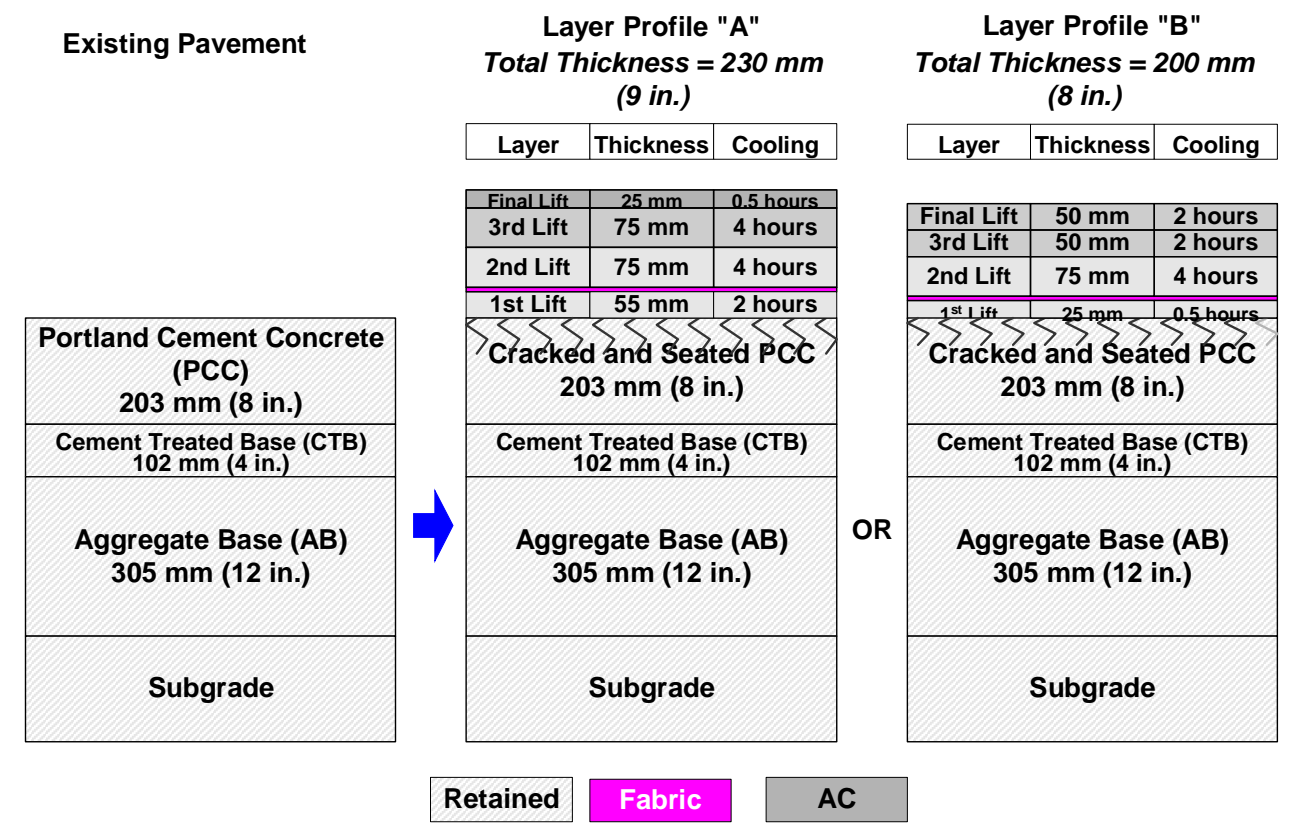

Figure 2. Two layer profiles for CSOL (Crack Seat and Overlay). 


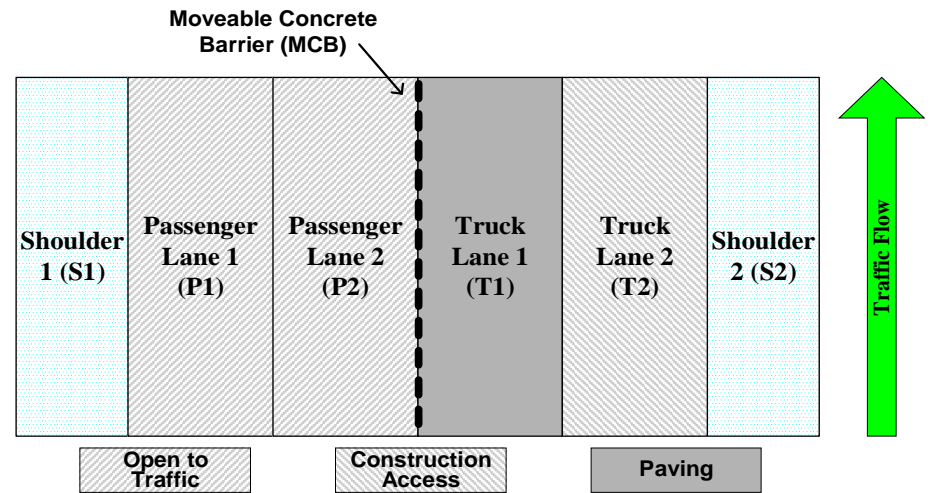

Figure 3a. Plan view of first and final stages.

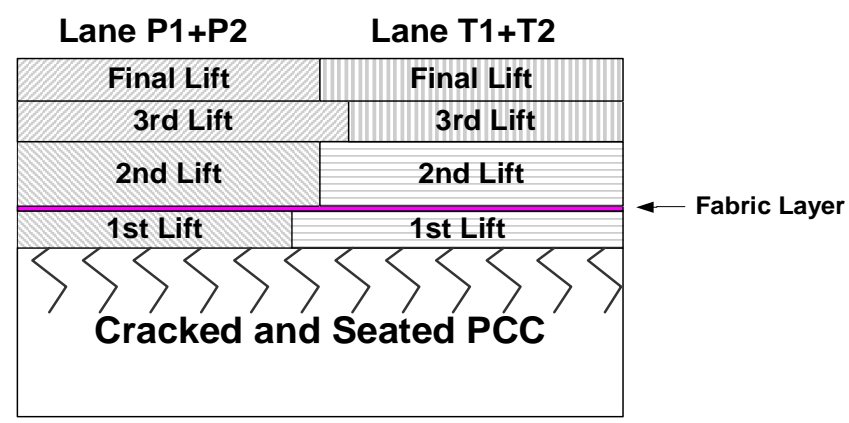

\begin{tabular}{|c|c|c|}
\hline $\begin{array}{c}\text { 1st } \\
\text { Stage }\end{array}$ & $\begin{array}{c}\text { 2nd } \\
\text { Stage }\end{array}$ \\
Stage
\end{tabular}$\Rightarrow \begin{aligned} & \text { Final } \\
& \text { Stage }\end{aligned}$

Figure 3b. Paving sequence (traffic must be switched twice during paving).

Figure 3. Detailed lane closure plan for CSOL Half Closure Full Completion. 


\begin{tabular}{|c|c|c|c|c|c|c|c|}
\hline \multirow[t]{2}{*}{ Existing Pavement } & \multicolumn{3}{|c|}{$\begin{array}{c}\text { Layer Profile "A" } \\
\text { Total Thickness = } 330 \mathrm{~mm} \\
\text { (13 in.) }\end{array}$} & & \multicolumn{3}{|c|}{$\begin{array}{c}\text { Layer Profile "B" } \\
\text { Total Thickness = } 406 \mathrm{~mm} \\
\text { (16 in.) }\end{array}$} \\
\hline & Layer & Thickness & Cooling & & Layer & Thickness & Cooling \\
\hline \multirow{3}{*}{$\begin{array}{l}\text { Portland Cement } \\
\text { Concrete (PCG) } \\
=203 \mathrm{~mm}(\mathbf{8} \text { in.) })\end{array}$} & Final Lift & $25 \mathrm{~mm}$ & 0.5 hours & \multirow{8}{*}{ OR } & Final Lift & $51 \mathrm{~mm}$ & 1 hour \\
\hline & & & & & 5th Lift & $51 \mathrm{~mm}$ & 1.5 hours \\
\hline & 3rd Lift & $76 \mathrm{~mm}$ & 6.5 hours & & 4th Lift & $76 \mathrm{~mm}$ & 1.5 hours \\
\hline Cement Treated Base (CTB) & 2nd Lift & $76 \mathrm{~mm}$ & 2 hours & & 3rd Lift & $76 \mathrm{~mm}$ & 6 hours \\
\hline $102 \mathrm{~mm}(4 \mathrm{in})$ & 1st Lift & $76 \mathrm{~mm}$ & 1 hour & & 2nd Lift & $76 \mathrm{~mm}$ & 1.5 hours \\
\hline$\square=$ & \multirow{2}{*}{\multicolumn{3}{|c|}{$\begin{array}{l}\text { Aggregate Base (AB) } \\
279 \mathrm{~mm}(11 \mathrm{in} .)\end{array}$}} & & 1st Lift & $76 \mathrm{~mm}$ & 1 hour \\
\hline $\begin{array}{l}\text { Aggregate Base (AB) } \\
305 \mathrm{~mm}(12 \mathrm{in})\end{array}$ & & & & & \multicolumn{3}{|c|}{$\begin{array}{l}\text { Aggregate Base (AB) } \\
203 \mathrm{~mm} \text { (8 in.) }\end{array}$} \\
\hline \multirow[t]{2}{*}{ Subgrade } & \multicolumn{3}{|c|}{ Subgrade } & & \multicolumn{3}{|c|}{ Subgrade } \\
\hline & $\overline{\text { ved }}$ & Retained & $\mathbf{A}$ & C & & & \\
\hline
\end{tabular}

Figure 4. Two layer profiles for Full-Depth AC Replacement. 
CSOL Production (lane-meters), Stochastic Analysis

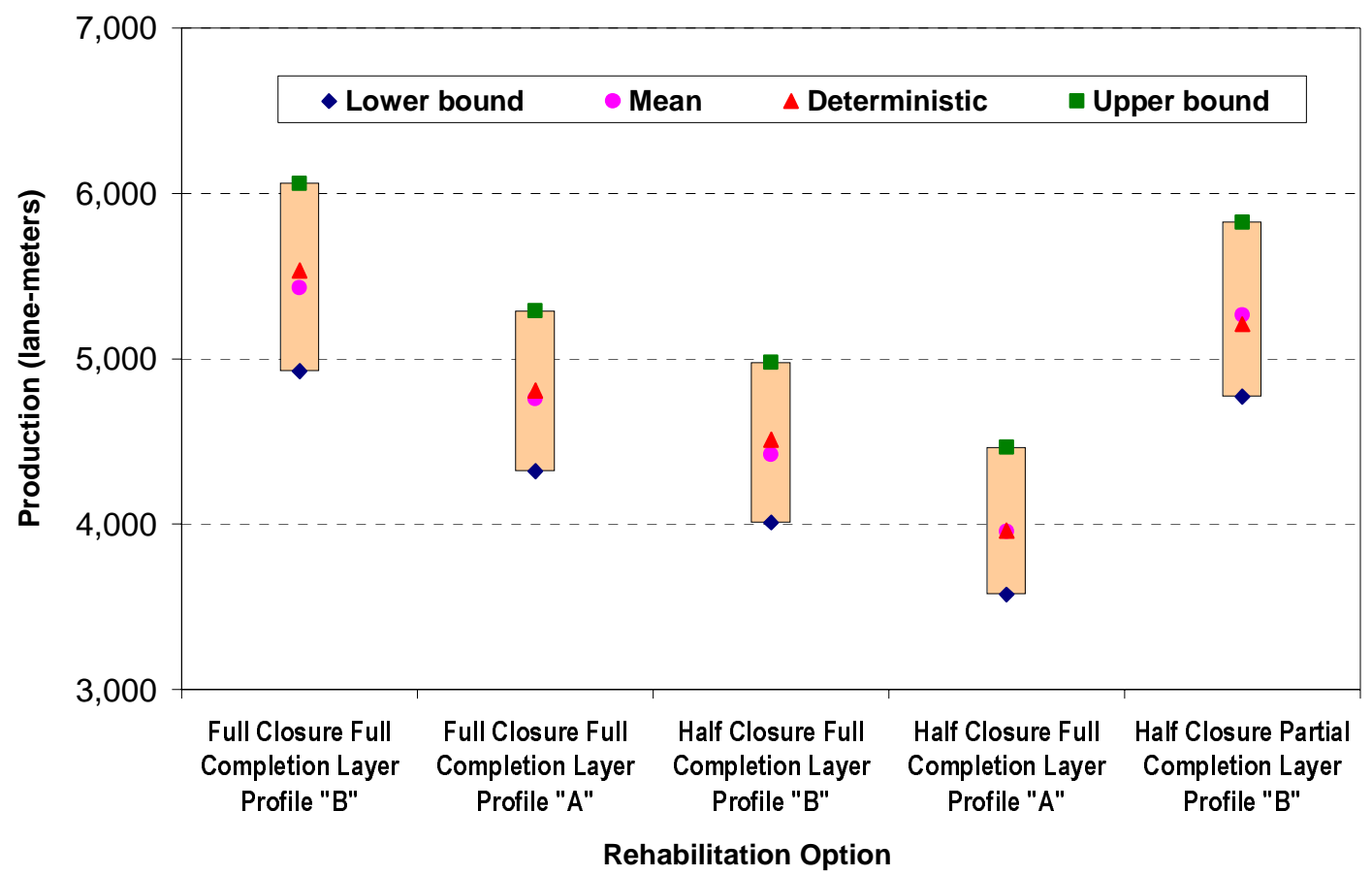

Figure 5. Results of stochastic analysis for CSOL production. 


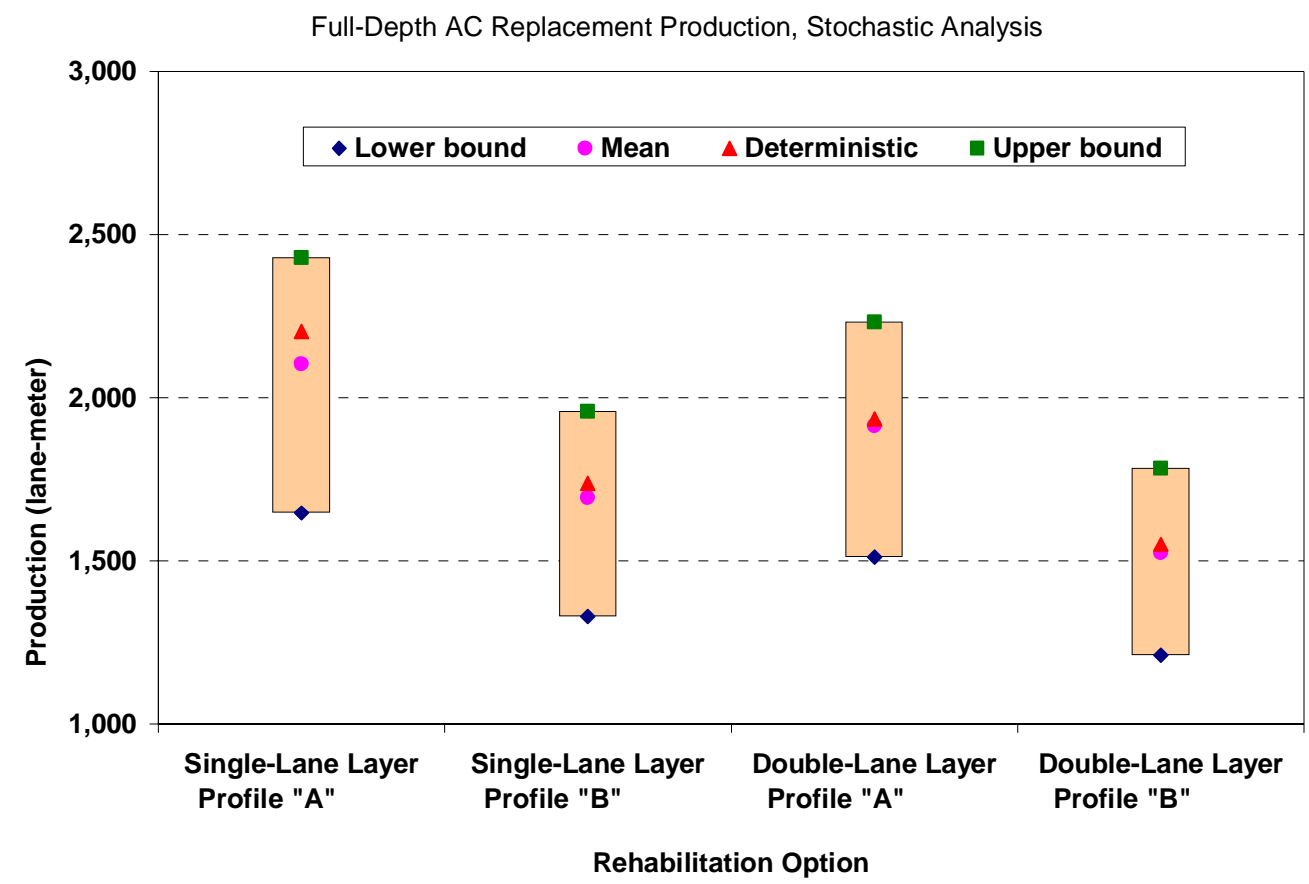

Figure 6. Results of stochastic analysis for Full-Depth AC Replacement production. 